\title{
RFID for Transparency, Traceability and End-of-Life handling of Textiles - The Importance of Harmonized Legislation
}

\author{
Lisa Schwarz Bour and Christina Jönsson* \\ Division Material and Production, RISE Research Institutes of Sweden, Sweden
}

Submission: December 20, 2019; Published: February 12, 2020

*Corresponding author: Christina Jonsson, RISE-Research Institutes of Sweden, Division of Material and Production, Box 857, SE-501 15 Borås, Sweden

\begin{abstract}
At present a lot of garments and home textiles are thrown away as soon as they are judged to be out of style or worn out. Only in Sweden over 200 tonnes of textiles end up as household waste every day. To achieve and strive for a circular economy, The European Commission has pinpointed textiles as one important focus area. As a consequence, it is important to significantly increase collection rates and textile material recycling. Development of new technologies are therefore required in terms of recycling processes at industrial scale, but in order to achieve this scaling, efficient and specific sorting processes are required. This sorting must be able to consider several parameters such as fiber content and composition, as well as possible presence of harmful chemicals, since these parameters have significant implications for subsequent processes. Information systems based on RFID technology, where digital information carriers bring the essential information to the end-of-life-handling of textiles is found to be a promising solution. By means of integrating RFID tags in garments and textiles, all relevant information needed for further handling at end-of-life can be made available. However, since July 2019, the RoHS directive includes category 11, a catch-all category. In category 11, passive RFID tags are covered, implying that garments with integrated passive RFID need to be CE-labelled. Apart from causing huge obstacles to reach circularity and transparency in the textile value chains, the legislation appears inconsistent to what the European Commission highlights as important for implementing the Circular Economy Package; which is the need for information systems, innovative tracing technologies and strategies for information sharing.
\end{abstract}

Keywords: Circularity; Transparency; Recycling; RFID; RoHS directive; Textiles; Information system technology

Abbreviations: EPA: Environmental Protection Agency; EPR: Extended Producer Responsibility; FTIR: Fourier Transform Infrared Spectroscopy; NIR: Near Infrared Spectroscopy; NFC: Near Field Communication; PA: Poly Amide; RFID: Radio Frequency Identification; RoHS: Restriction of Hazardous Substances; ROI: Return of Investment; QR: Quick Response; UHF: Ultra High Frequency

\section{Introduction}

The shift to a circular economy requires the prevention of waste and that most of the material, that is now seen as waste, is instead recognized as a material resource. The EU Commission's Circular Economy Package emphasizes the need for efficient utilization of raw materials and resources within the EU. The reasons for this are reduced climate impact as well as secure access to raw materials, but also that new jobs are created by increasing reuse and recycling. Also, the goal is that the use of recycled materials should be safe from a health and environmental point of view by avoiding the circulation of hazardous substances as far as possible while resource-efficient circular value chains are sought. In a circular economy, a non-toxic textile raw material is a prerequisite, which means that recycled textile fibers must stay below the limit values for chemical content. In textile manufacture a variety of chemicals are added to give the textile products different properties. It can range from a specific fashion colour to adding dirt- and water repellency. Some chemicals are washed out of the goods before coming to the consumer, but in some cases, chemicals remain in the textile. Therefore, when textile goods are to be recycled, it is important to know which chemicals are present and in which amount. Retail involves complex textile materials composed of several different fiber types, with different dyeing systems and surface treatments. To enable traceability and ensure an effective sorting process, able to take into consideration fiber 
composition and chemical content in used textiles, new adaptive methods are needed for identification of textile products. The use of digital information carriers integrated into garments has the potential to greatly increase future traceability throughout the supply chain, but also to facilitate subsequent processes and lay the foundation for circular textile value chains.

A system based on RFID-tags, with multiple functionalities responding to the needs of different actors in the textile value chain, is the future vision for a resource efficient textile handling system. Important aspects to take into consideration are information system model and architecture, system for data collection, overview of existing standards and mapping of standardization need, cost calculations and evaluation of ROI, as well as implications of integrating digital information carriers in textile products.

\section{RFID technology as a promising solution to reach circular textile value chains}

RFID technology has developed rapidly in recent years and is a very attractive potential solution to significantly increase transparency, traceability and end-of-life-handling of textile materials. An RFID tag can carry a large amount of data and is read when it is within range of a reader. At reading, the tag can be located in the middle of the garment and covered with fabric (integrated) without affecting the quality of the reading. This greatly facilitates handling compared to, for example, barcode/ QR systems, which can neither be read from a distance nor carry the same amounts of data. In addition, barcode marking must be picked out of the garment and displayed to its reader, which is not the case for RFID. An RFID system can be used adaptively and allow sorting of textiles based on the parameters specified. For example, the system would allow sorting out textiles containing a certain undesired chemical, which has been regulated since the garment was produced. Alternatively, it would be possible to sort on simple parameters such as colours and sizes (for reuse) or on process parameters such as the dyeing system used (e.g. useful for chemical recycling by depolymerization). The technology would quickly and efficiently sort out textiles in a wide range of fractions according to the selected parameters, thus providing access to textile volumes suitable for different types of recycling techniques in a very efficient, fast, accurate and safe way with very small margin of error. An established technology of this kind directly influences the possibility of high value material recycling of textiles, returning it into the material cycle as a resource and preventing waste.

In addition to laying the groundwork for completely new prerequisites for sorting and recycling textiles, labelling and tracking by use of RFID technology can also help manufacturers, wholesalers and retailers, as well as end-users and consumers, through improved information across the entire life cycle and value chain. Improved inventory management, automated inventory, diminished losses and thefts are some of the quick and visible effects. In sorting facilities as well as in stores, the RFID technology has significant effects on the working environment as several monotone and time-consuming steps can be automated and chemical exposure avoided. It provides better efficiency throughout the supply chain through lower costs and more effective routines. It also provides safer quality tracking with traceability throughout the supply chain, resulting in lower costs due to simplified return management at all levels and minimized risk of counterfeiting. For a system like this to be possible, it needs to appeal to all actors in the textile value chain, something that will not only aid in implementation but also to carry the cost of the technology. In the case of RFID, there are many functionalities that can be envisioned, e.g. using the technology for our clothing to communicate with the washing machine-imagination is the limit. Increasing the availability of information on textile items is important as it largely affects the possibilities of reuse and material recycling. Information is key when it comes to the material being used to its highest potential and incineration significantly reduced. Radio Frequency Identification (RFID) is one of the most important connectivity technologies and a technology which can enable and prepare our future proactive data systems.

RFID is a method of identifying unique objects using radio waves; the technology consists of a reading device that communicates via radio waves with an RFID tag. This tag has a unique identity but can also save external data in separate memory spaces such as data bases, that can be retrieved or changed. With the help of RFID technology, immediate traceability and identification of tags within reading distance is possible. Recent developments in nanoelectronics allow mass production of new RFID silicon circuits at very low cost, enabling new applications, such as traceability and identification of textile materials. The most interesting information carriers for retail are passive RFIDtags, without battery, which is far more environmentally friendly and guarantees long lifetime. These tags can be read by fixed readers as well as simple and cheap hand-scanners. Today, RFID is being used by some brands for logistics and inventory, using their own individual system for tags, meaning that only the product owner can use the information. However, the use of these tags is at a very basic level in terms of information content and the tags are located in the paper hangtag of a garment that is being removed and thrown away as soon as the item is sold. The other alternative tried out is to place the tag inside the anti-theft device, either way the tag does not follow the garment. The vision of a system based on integrated digital information carriers reaches much further, using carriers that are integrated and follow the textile product all through its life which opens a range of other possibilities, many of which have already been mentioned.

A system-solution does increase the demand on the RFID tag used, as it needs to be robust, while at the same time small, thin and flexible. It also increases the need for cooperation across industry 
sectors and involves working together with standardization organizations in order to achieve a system built on a solid foundation and a system that can be used on a global scale. The need for a technology, able to handle mixed and complex materials on a large scale and for keeping track of chemical content in used garments, is pointed out in report Textile-to-Textile Recycling, issued by the Nordic Council of Ministers (2017) [1]. Access to more detailed information is desirable and RFID is in our opinion the best technology available that can offer all the requested functionalities in the textile value chain. It is important to note that building the information database system is the heart of the technology. If desired; RFID can be combined with short-distance NFC communication during the initial period of implementation as NFC devices operate at the same frequency as UHF RFID readers and tags with the same protocols. Northern Europe were early adopters of an efficient wastepaper system and have wellfunctioning systems for handling, for example, electronic scrap, packaging, batteries, return glass, soda cans, etc. These systems are also highly accepted by the public. In the area of textile handling, the situation is very different with low collection rates in most European countries. To give an example from Sweden, more than 200 tonnes of clothing and textiles are discarded daily through the household waste, although collection has increased by $27 \%$ in the last decade according to a recent report, issued on assignment by the Swedish EPA (2018) [2]. This is an incredible waste of resources and the potential to reuse or recycle large parts of this volume is of course significant, but requires a very efficient sorting system, especially when collection rate increases further.

Moving towards a circular economy for textiles, crosssectoral cooperation and working together with standardization organizations is key. Many countries in Europe currently has neither large-scale, high-value material recycling of non-reuse textile waste, nor any major sorting plant. Textile waste is mainly incinerated, or in the worst case placed in landfill, due to deficiencies in the collection and sorting system, in addition to limited possibilities for using other recycling methods. Combustion of textiles originating in fossil raw materials should be avoided as this contributes to increased greenhouse effect. By enabling fast and efficient sorting and thereby allowing high-value material recycling, our hope is that the use of recycled textile as a raw material for new products will be facilitated and accelerated. Europe adopted the Circular Economy Package in 2018. Sweden, as a frontrunner in this field, set out clear objectives for increasing both the collection and recycling rate of textiles by 2025 (Swedish EPA 2016). If these highly set goals are to be achieved, both collection systems, infrastructure and logistics solutions must be established. In addition, a powerful information campaign needs to be implemented and several material-dependent recycling techniques commercialized. However, all of this will be very difficult to achieve without efficient, automated textile sorting with access to individual material composition, chemical content, etc. This in turn requires the use of robust, customized information carriers and a connected information system. Looking at the goals set by the Swedish EPA, the increased need for reuse and recycling in Sweden translates to $47 \mathrm{k}$-tonnes textile per year. The trend is evident, as many countries are now discussing the implementation of EPRs for textiles, with Sweden being one of the first out.

As legislation becomes a reality regarding handling of textile materials, effective sorting and recycling methods will be urgently needed. Regardless of whether the solution is the implementation of a producer responsibility or the application of a compulsory sorting requirement for municipalities, the same needs will have to be addressed. The large flow of textiles needs to be sorted into well-defined volumes and here, RFID technology is a very attractive solution for fast, automated and cost-effective sorting. Today, most of the linear systems must be transferred to a circular system through technology development and increased knowledge. When collected textiles can be effectively sorted into different streams, the resulting textile raw material can find a new life in a completely different product category. By using a variety of recycling methods and so-called open loop recycling, this goal can be achieved. Of the total volume collected textile there are of course some pure materials and commonly used blends such as cotton/ polyester. However, looking at the total volume, the majority of the textile consists of fiber blends. In order to recycle textile materials in the best way possible, efficient and specific sorting is required, this is the case for chemical and mechanical recycling processes alike. To give some examples, the chemical recycling of cotton into fiber of viscose-type requires a high cotton content as too high levels of other fibers yield a product of lower quality. Looking at chemical recycling of polyester, some processes are sensitive to the dyeing system used and would therefore benefit greatly in getting access to relevant information on additives and dyes. Also, for polyamides this is important, for example PA 6 and PA 6,6 can be recycled if separated, whereas a mix of the two will cause problems in processing due to different processing temperatures.

For mechanical recycling of textiles there are similar requirements, as these processes also depend on several parameters such as fiber composition, construction and colour. Common for all types of recycling technologies for textiles, chemical as well as mechanical, is that efficient sorting is a prerequisite for good quality of recycled materials, continuity of volumes, scalability and cost-effectiveness. For chemical recycling processes to be economically feasible, they must effectively have access to requested fractions. In the same way, the quality of the output from mechanical processing depends to a great extent on what material enters the process. In other words, effective sorting is an absolute requirement for a well-functioning textile handling system, whether we are talking about chemical or mechanical processes. A sorting that only refers to producing limited fractions will also not be economically viable, but if, on the other hand, we 
sort out several fractions for further processing into raw materials, then the situation is different and the potential for a good economy in the system increases. In addition to a great need for information, access to this data must also be very quick in order for the system to be economically feasible, especially when it comes to end-oflife sorting. Compared to systems based on FTIR/NIR, an RFID system has many more functionalities and will provide much more detailed information about origin, material composition and chemical content, as well as basic item information. FTIR/NIR technologies will be a useful complement for handling non-tagged items but these technologies are limited to sorting based on the main fiber components.

The particular attractiveness of a digital information system based on e.g. RFID is that it enables the same technology to provide a large number of functionalities throughout the value chain, including logistics, customer communication and endof-life handling as previously described. A system populated with standardized data and information should not be subject to business models that are built on making a high profit on repackaging data. Instead, a controlled open-source data system, revealing data only to authorized, appointed actors is preferred. On 16.1.2018, the European Commission published a communication to the European Parliament, the Council, the European Economic and Social Committee and the Committee of the Regions. This communication is on the implementation of the Circular Economy Package in regard to options to address the interface between chemical, product and waste legislation [3]. In this document, the need for access to relevant information on products for all actors in the value chain is expressed. The document highlights the need for information systems, innovative tracing technologies and strategies which could enable relevant information to flow along article supply chains and reach recyclers.

\section{RoHS directive implies CE-labelling}

As has been described, the future information system is dependent upon an information carrier, making sure that the important information about the product can be used further downstream, enabling a resource efficient system for textiles. In the area of circular economy, there are several conflicting policies and directives, especially regarding waste, chemical and product legislation. The interface between these areas need to be harmonized in order not to hinder circular material flows. In addition, it is important that we do not have legislation that hinders the technological developments needed to implement efficient textile handling and information sharing. A directive that today may pose a risk is the RoHS directive, focusing on electronic and electric equipment. In July 2019 category 11 was introduced, where passive RFID tags are included [4]. This implies that all tagged materials and products need to comply with current RoHS regulation. Apart from having specific substance restrictions, the RoHS directive also enforces CE-labelling. If every garment with an integrated passive RFID tag would need to have a CE-label, this would be a large obstacle for these developments, trying to do 'good' regarding the situation for chemical use and chemical compliance. For textiles, chemical compliance with RoHS restricted substances is not a problem. However, the documentation which needs to be provided according to CE standards and the CElabelling procedure itself is not something the industry can easily handle and is therefore very problematic. It is necessary to take these implications into consideration for RoHS, as it may stop or significantly delay and hinder the development towards circular value chains.

\section{Conclusion}

Our standpoint is that it is important to reach consensus in the textile industry as well as in the circular value chain (collectors, charities, sorting facilities, raw material producers among others) regarding systems for increased traceability and transparency. Standardization has the potential to pave the way for consensus among actors and will be an important instrument in the circular system. Terms and definitions are of great importance as the requested information needs to be unambiguous. It is also of great importance to demonstrate (small scale and early on) a system which is attractive to different actors in the value chain; which greatly enhances the market pull. Today, the value of the collected textile that cannot be reused has a low value as a secondary raw material, largely due to the difficulty of sorting different materials efficiently, as well as uncertainties in the chemical content. If the garment instead would carry information about materials composition, chemicals, etc., the value of secondary material would increase significantly. In addition, it is important there is no legislation that hinders the striving for technological development, needed to implement efficient textile handling and information sharing, enabling closing the loop of textile materials. A directive such as the RoHS directive, that may enforce CE-labelling of garments with integrated passive RFID tags, would be a large obstacle for the development towards circular value chains.

\section{Acknowledgement}

This research was funded by Swedish funding agency Vinnova within the Tex.It, which is greatly acknowledged. Additional funding provided by XPRES (Initiative for Excellence in Production Research) is also gratefully acknowledged.

\section{References}

1. Watson D, Gylling AC, Andersson T Elander M, Heikkilä P (2017) Textile-to-textile recycling: Ten Nordic brands that are leading the way. Nordic Council of Ministers 753: 1-48.

2. Belleza E, Luukka E (2018) on assignment by the Swedish EPA. SMED Rapport nr 2, pp. 1-9.

3. European Commission Staff (2018) SWD. 20 final.

4. EUR-Lex - 02011L0065-20190722, RoHS Directive. 
Your next submission with Juniper Publishers will reach you the below assets

- Quality Editorial service

- Swift Peer Review

- Reprints availability

- E-prints Service

- Manuscript Podcast for convenient understanding

- Global attainment for your research

- Manuscript accessibility in different formats ( Pdf, E-pub, Full Text, Audio)

- Unceasing customer service

Track the below URL for one-step submission https://juniperpublishers.com/online-submission.php 